recommends that no part of a final or qualifying examination should be taken before the end of thirty months of clinical study, and that the examination should not be completed before the end of the period of clinical studies of thirty-three months. (5) It has abandoned the recommendation of 1933 that candidates should be required to complete the three portions (medicine, surgery, and midwifery) of the final or qualifying examination within a period of nineteen months.

It would be less than frank not to add that the Council's decision on the last point was not inspired by sympathy with the chronic student but by confidence that examiners can be trusted to guard the public against candidates incapable of passing at a reasonable standard. In short, the aim of the General Medical Council is to ensure that the medical practitioner will not (to borrow from $H$. A. L. Fisher) have to navigate the sea of knowledge without the charts and compass of an adequate education.

\section{PSYCHOLOGY IN MEDICAL EDUCATION}

BY

JOHN RICKMAN, M.D.

President, Institute of Psycho-analysis, London

An important event in the professional life of every medical man, if not the most important event, is his dealing with patients in the first months of general practice. It is the first test of the young practitioner; it is also of course a test of his professional education. This article will discuss some of the difficulties, and the reasons for the difficulties, in the transition from student to practitioner, with special reference to the acquisition of professional skill in and understanding of the relation of a sick person to his medical adviser.

\section{Changes in Medical Education}

There are two ways in which a doctor can get instruction. He can be taken by his teacher into the patient's environment and be told there what factors have led to the ailment, what difficulties lie in the way of the remedy, and what chances there are, all things taken into consideration, of recovery. The teacher and his pupil make an entry into the patient's life, they enter his region of "social space" and do what they can to bring some easement within it. The apprenticeship was an example of this kind of medical education. The second, the more modern way, is different: the patient is drawn into a region where he is isolated from usual social contacts and interests, and is examined by a number of hospital departments which have specialized on one or other aspect of the mechanism of his body or mind. The criterion on which the laboratory departments report is basically a statistical one: the findings lie within the normal limits for the age group of the patient examined.

Contrasting these two generalized methods of instruction and calling the former "individual or apprenticeship" and the latter "statistical or hospital," we can see advantages and disadvantages in each. When there is but one instructor, usually unsupported by the large and complicated apparatus of a hospital organization, the latest discoveries in physiology and pathology are apt to suffer some neglect ; there is pressure exerted on both teacher and pupil by the environment of the home to consider before all things the present emergency, including the social and financial strain of having a sick member on their hands. The patient is seen in the world in which he lives. Under such conditions it is admittedly not easy to examine in detail the workings of his various organs, but it is difficult not to see the way his life is tied in bonds of affection and dislike, in aspiration and despair, to his relatives and the social group of which he is a member. The apprentice to the general practitioner penetrated into the home and stood both to gain and to lose by that medical relationship.

A patient sent to hospital (to use the usual phrase) enters an unfamiliar region of social space. Within that organized system of research and therapy the easiest objects of study are the "parts of the machine"-those portions of the individual patient which are most susceptible to test and measurable reaction. In such an environment of isolation from the personal and social forces which act upon the personality it is difficult to get a comprehensive understanding of the personality of the patient. An over-all view is a greater achievement of clinical synthesis in a hospital than in a house; a thoroughgoing mechanistic analysis of the patient is more difficult in the home than in the ward.

The task of medical education is to develop fully the capacity both for clinical synthesis and for mechanistic analysis. The questions arise: What conditions most favour this double development? What factors make those first few months of general practice something to be anticipated with dread and looked back on with relief as a thing long past? That many practitioners are eased in this transition by the senior partner of the firm they join, and thus enjoy a postgraduate apprenticeship, shows that the present-we do not know yet about the future-organization of medicine can allow the filling up of this gap in technical education.

\section{How does the Doctor Spend his Day and his Energy ?}

Odd though it may seem, there has never been a "job analysis " of the doctor's working day, or, if such an investigation has been made, it has received almost no publicity. It would appear that medical education has developed without a detailed reference to the job for which the student is being trained. How much of the doctor's time and how much of his skill are employed in the diagnosis and therapy of injuries, disorders, or normal processes-for example, confinements? How much of his day is given to specific planned acts of therapy, how much to diagnosis, and how much to travelling? Nor do we know how his time is divided between the age groups, the occupation groups, the income groups, or disease groups, or how far the proportions vary with urban and rural and other social and geographical divisions.

Important as these facts would be, one would think, both for teaching and for planning the future of a health service, even such an investigation of the relatively easily measurable units of time would ignore the subtler but perhaps more important factor of "concern." The doctor has concern for his patient: he is worried if he does not know what is wrong with him or how to bring him relief for his suffering. It is this concern which makes him feel the personal and human value of his work in the social-or, if you will, the spiritual-life of the community; it is something which makes him regard the financial return as only a part of the reward of his profession.

This factor, so important to the vitality of the profession and to its growth, cannot easily be brought within the scope of the mechanistically oriented education of the student. One does not have this concern-feeling for organs but only for a person, a fellow human being; one cannot book-learn it, it comes from a personal relationship.

The worries of the first few months of the general practitioner's life, or even the first few years, spring not from a need to harden his heart to suffering but to soften it so that he can feel his way into what the patient is going through in his suffering and yet keep his head. It is the attribute 
of professional competence to appraise the feelings of the patient, through sympathy with him, without losing objectivity and judgment of the situation as a whole. To get this over-all appraisal of the situation is often one of the main motives which lead the patient to seek professional advice, and the doctor cannot give it unless he has faced all the issues which confront his patient.

Though the patient may have to move into the " hospital area " of social space and the doctor may have to move into that of the "family area," the appraisal can best take place in the neutral ground of the doctor's consulting-room. He must make it neutral to all influences and prejudices if it is to act as a "diagnostic and therapeutic area" in which patient and practitioner can both move with ease and mutual understanding.

\section{The Medical Interview}

One thing must be assumed in medical work: a patient never consults his doctor without good and sufficient cause. He may make a great fuss over what seems a trivial complaint, or he may dismiss as trivial symptoms of the gravest significance, but the cardinal fact is that he has come to a point when he cannot manage by himself something concerning himself-there is a breakdown in adjustment processes. Let us leave on one side those seemingly easy cases -for example, a cut hand needing a few stitches (though even such events may be indicators of accident-proneness or some such short-cut solution of a long-standing trouble)and all of those cases which occasion the doctor no concern. What remain? Just those cases-and taken over the year how numerous they are!-where the physicalmechanistic solution to human suffering has failed.

Two questions the practitioner has to put to himself: What is wrong? and, no less important, How ill is the patient? A repetition of a visit to the surgery with the same worried expression about the same "trivial" complaint, or a new one equally trivial, is a distress signal: the degree of the maladjustment is not to be measured by the degree of dysfunction of the organ system complained of-the patient is more ill than his body gives warrant for. What should the doctor do-judge the situation by the sole criterion of physical disability and dismiss the rest as "imagination," or assume that where there is much complaining there is something paining? And if this be the case, how does one discover the cause if it is not in the body? Is the registered medical practitioner to have traffic with the woes of the soul? Perhaps he need not go quite so far.

It was said that the consulting-room should be a sort of neutral ground where everything can be considered dispassionately (which is not the same as cold-heartedly) and without prejudice. If the patient has some worry on his mind his original complaint may be only a point of entry to the consulting-room, where he wants to get rid of his burden. Then the important thing is not only to let him talk but for the doctor to let himself listen. When it has been acquired, the art of listening is not a tedious one-way traffic but a technique of getting the patient to unfold the life-history of the suffering lying at the root of his present complaint as it is to be seen in the framework of the development of his personality as a whole: a historygiving rather than a history-taking. How can this art be acquired?

\section{No Research without Therapy ; No Therapy without Research}

This is rather a grand way of saying, among other things, that between patient and practitioner there must be a twoway traffic.
The sufferings which lead to "trivial or pointless complaints," no less than an easily spotted neurosis, are basically hidden from and are confused for the patient himself ; they are bound up with the development of his personality and are an expression of conflicting trends within it. If their solution were easily within his capacity he would have solved them long ago; the fact that he comes to his doctor is sufficient evidence that his powers of adaptation have for the moment at least broken down. He cannot cope with the present problems of his life because he has to solve and satisfy unresolved and uncompleted emotional situations of the past. The aim of the interview is to allow the patient to disclose as fully and as freely as possible the history of his development. This disclosure the doctor must meet with sincerity of purpose and dispassionateness and he must not lose patience in the face of failure.

These qualities are among those which are prerequisites in the research worker. The solving of the problem of mental pain in the individual patient is not possible without this research quality in the therapist, and his greatest contribution to the two-way process is less often advice than an understanding of the problem at issue.

Research workers who try to invade the private lives of human beings to wrest from them answers to abstract research problems seldom get far with their researches into the cause and cure of mental suffering, and their work usually remains in the academic library for which it was written. People can disclose the sources of their mental suffering only during the actual experience of relief of that suffering. The so-called " normal psychology," which takes no account of the influence of pain, anxiety, guilt, and grief on human behaviour, need not for long detain the medical student in his preparation to deal with people and their problems in real-life situations.

\section{Is Psychiatry yet Another Specialty?}

When a patient comes into a consulting-room the doctor has before him only the small segment existing in the present of an organism with an extension in time. This organism, as was recently said by a writer in the Lancet, began as a speck of jelly and will end some day as a lifesize corpse. It grows by constant interaction with its environment, passing through different physiological phases and as many different psychological and social orientations. The egoism of the infant partly gives place to the passions of love and rage of the child (both, often and most embarrassingly, directed to the same person), and later to the stormy mixtures of adolescence, then to a fairly stable maturity, and finally shrinking in body and mind in old age (Shakespeare has said that better, but it bears repetition). Each age and stage has its problems, which when unsolved are never completely left behind: the doctor has to listen for the murmur of those old and unresolved complaints beneath the apparent preoccupation with present ills.

The study of these problems is called psychopathology; the application of such knowledge to the suffering of the individual is a part of psychiatry (and of groups, "sociatry"). The training of the student to elicit a history (the muchguarded history of the development of the personality) is one of the duties of his psychiatric teachers. Training for the assessment of the retardations of development, intellectual and emotional, is also part of psychiatric teaching.

The whole range of neuroses, marital maladjustment, character disorders, delinquency, and insanity; the wider range of so-called psychosomatic affections, and the still wider range of mild and temporary worrying upsets (which are partly due to misery of spirit or insecurity, to lack of love or incapacity to give and receive affection and find 
rest of body and mind)-all these are medical problems which get help from psychiatry, and sometimes only there. Is psychiatry a specialty? It stands outside the physicalmechanistic separatism which was till perhaps recently the prevailing convention in modern medicine, for if it is to do its job it must take a wide and time-spanning view of the personality in its social setting: it is of course no less a specialty than medicine itself.

\section{On Bringing the Student to the Patient}

(a) The medical student should be brought at an early stage in his career into relation with patients. For example, when dissecting he should have periodic turns of duty as a dresser in the casualty out-patients department; even a sprained wrist or ankle should be seen in relation not only to anatomy but also to social disability. The young student should be relieved of some of his load of corpses and learn to carry live burdens. (Some of the apparent immaturity of the medical student is a reaction to the abstract and impersonal nature of his studies, which frustrate his clinical inclinations. It is a sad thing that the student's first "patient" is a corpse.)

(b) Much more time should be lived in medical institutions. Even in the pre-clinical years the student could learn some of the routine of the ward as a student orderly, both to have an insight into how patients behave and what they feel when doctors are not present, and to get some first-hand knowledge of the ward as a community. A few weeks in epileptic and mental defective colonies, in tuberculosis and other sanatoria for chronic cases, would widen his understanding of the chronically sick. His status on some of these visits would be nearer to that of the nursing than the medical staff; on others he should go as assistant to the doctors.

I might illustrate the value of the good nurse's approach to a case by the following example: A patient in a public ward suffered from nocturnal attacks of respiratory and other kinds of distress. His house-physician and the registrar were asked by a doctor patient in the same ward, as a matter of professional interest, what precipitated the attacks. They did not know ; medical examination gave no clue. The patient's nurse was asked and gave an answer without hesitation: the attacks followed the visits of a particular relative. Two comments here: first, the nurse, whose knowledge of anatomy, physiology, pathology, and clinical medicine was of high nursing standard, used that knowledge in a quite different way from the house-physician and registrar: the latter made it the sole theoretical instrument of aetiology and diagnosis; the former (perhaps freer because she had no self-imposed duty to limit her thinking to what she read in books) was able to observe the facts as a whole. The doctors had not asked about the effect of visitors; it had not, presumably, come into their theories of aetiology. The second point is that the nurse observed the patient in a wider region of biological activity, that of the family-that is, in a social setting. The doctors saw only what lay in the bed, not even what came to the bedside. Which, in this case, was the more clinical and which the more veterinary observer? Of course, such a question should not be put: it is a question framed with reference to "academic subjects" and not to scientific method. Rather let us ask, Which of the two provided himself or herself with the greater number of frames of reference, and used them in an integrative way?

Speaking aphoristically, the best medical instruction is clinical -that is, bedside. If the patient's illness and not "a disease entity" be the subject of instruction, the best bed for this purpose is the patient's own, the next best is one that the hospital pupil has to be responsible for, the third best is that which is in hospital and which someone else looks after: the first educates the G.P., the second the nurse; the medical student in this respect comes off third best. I am referring to learning about the illnesses of actual people, not about diseases; and, further, I am saying no more than that this kind of bedside or clinical experience-though it does not come into examination-ridden curricula-is important for the student and the young practitioner.

(c) He should at first be taken by almoners and psychiatric social workers, and later go alone, on follow-up visits to a selection of the patients he has seen and treated as out-patients and in the wards. He should realize how large is the gap between the " social space" of the family and that of the hospital, and he should be taught the techniques for lessening and bridging that gap-for example, the endeavours made increasingly nowadays to create within the hospital and convalescent home transitional communities where the recovering patient can make an effective rehabilitation.

(d) He should have experience in all branches of the mental out-patients department, in intelligence testing, in the social workers' department, and above all in the practice of psychiatric interviewing.

(e) He should interview relatives of patients with the same care as patients themselves-time spent on learning interview technique is repaid a hundredfold in his general practice.

( $f$ ) Anything that brings the student to the patient, to his home, to his factory should be welcomed, and will help to make the transition from medical school to professional life as easy and as fruitful as possible.

(g) Medical education should proceed on the principle (hard though it be to apply) that knowledge gained through the shouldering of responsibilities is the best sort of medical knowledge to have.

\section{On Using the Ex-student's Experience}

A sample survey might be made one, two, and five years after leaving medical school, asking general practitioners what comments they would like to make on the curriculum of their training. Such opinion-taking would be specially useful to estimate the desirability of continuing experimental changes in the curriculum and dropping those that were not expedient.

\section{The Doctor-Patient Relationship}

An experiment is in train to evolve a national health service. The stability of the profession vis-à-vis the patient population will ultimately depend on the doctor's capacity to meet the patient's need to be understood as a person. If treated as a merely physical mechanism composed of parts and system the patient will turn more than ever to self-medication or to unqualified persons. The existence of quacks* is a reproach to the training and to the practice of the regular profession. (A survey of medical needs and medical aids, if realistic, would have to include the activities of the quack, his clientele, and his method of work.)

* A quack may be defined as a person who seeks to establish a quasi-professional relation to a client (or patient) without having first submitted himself to a course of training regarded as adequate by the teachers in that profession; who makes no consistent by the teachers in that profession; who makes no consisters of the profession to the body of knowledge already existing - to the end that the range of experience of the next generation of students may be improved; who when in a difficulty with diagnosis or treatment does not call in a brother-practitioner, laying before him all the facts known, being ready to accept the advice offered, him all the facts known, being ready to accept the advice offered, to put his experience fully at his disposal and return the patient to his own practitioner, not trying to keep him for himself; and who is unwilling to submit himself to the discipline of the organizations of his profession in matters affecting his ethical relations to his patients:

The definition turns on four things: on the willingness to learn in due humility from an older generation, to give without arrogance to the next generation, to treat one's own generation with generosity as equals, and to submit to a social code.

Most of the articles on quacks and quackery enlarge on the practitioner-patient relationship; ought not more consideration to be given to the relation existing between persons in the same fieid of social activity-namely, brother practitioners? 
The remedy for the problem of unqualified practice lies in better medical qualification-a training which meets the needs of those worried and distrusting patients who cannot define their ills and who turn from one adviser to another till they find a listener.

The organization of a national health service will fail of its purpose if scope is not given in fullest measure for the relationship between doctor and patient to be one of personal trust and confidence and that continuity of interest in the individual patient which springs from professional "concern.".

\section{STATISTICS IN THE MEDICAL CURRICULUM?}

\section{BY \\ A. BRADFORD HILL, D.Sc., Ph.D. \\ Professor of Medical Statistics at the London School of Hygiene and Tropical Medicine}

In maintaining, with customary vigour, the value of statistics in the furtherance of medical research Prof. F. A. E. Crew was fain to admit that "the very mention of the word 'statistics' evokes a peculiarly strong emotional reaction on the part of the great majority of medical men and women. I think it is fair to say," he continued, "that by the profession as a whole an ignorance of, and a scornful and distrustful attitude towards, statistics are regarded as the praiseworthy attributes of a robust personality." 1 Whether that attitude is a prerogative of the medical profession is of course gravely open to doubt. The daily misuse of statistics of every shape and kind perhaps makes sceptics of us all-or, far worse, leads us to accept uncritically figures which fit in with our pet beliefs and to reject, equally uncritically, those that do not. With the doctor it may be, as I have suggested elsewhere, ${ }^{2}$ that both selective and environmental factors contribute to this state of "allergy." The person who is taking up medicine as a career may well be one whose interests lie mainly with individuals-sick persons-and far less, if at all, with the statistical concept of the group. In his clinical training this attitude may be further encouraged by concentration on the specific case, by too close an attention to the average to the neglect of the variation round it, and by a communicable distrust passively or actively transferred from the teachers to the taught in a field in which controlled experiments are notoriously difficult.

\section{The Present Dangers}

However that may be, there is no doubt, I should say, that the present generation does look with rather more favour than the past upon the statistical approach to the problems of medicine, in the curative as well as in the preventive field. A superficial study of medical journals is sufficient to reveal that-in spite of the gloom which much of the flow of literature must continue to inspire in the mind of the statistical enthusiast. While that change isto the statistician at least-all to the good, it may yet bring, I believe, its own dangers. Such dangers will arise if the writer or the reader does not really understand the basis of the methodology that is being applied. For instance, we may run the risk of passing from the situation in which it is too readily concluded that the reactions of Group A, treated in one way, differ materially from the reactions of

1 "The Role of Statistics in the Furtherance of Medical Research., Trans. Faculty of Actuaries, 1945. " Statistics in Medicine." Trans." Manchester Statist. Soc., 1947.
Group B, treated in another way, when in fact such a difference might quite easily have arisen merely by chance with the numbers involved, to the other extreme when, overawed by a spate of \pm signs and technical tests of significance, it is humbly accepted that it is "mathematically proved" that Group A does differ from Group B and that therefore this must be due to the treatment, which as logic is even more indefensible. In other words, the uninstructed or half-instructed may be just as easily misled, perhaps more easily, by an appearance of " mathematical" exactitude as by the simpler and more oldfashioned methods of mishandling figures. If that were to occur, aided in other fields by the readiness with which right- or left-wing enthusiasts will continue, consciously or unconsciously, to find figures to fit their fancies, the pendulum will doubtless swing back and bring to the fore again the belief that statistics in medicine can be made to "prove" anything and are to be eschewed.

If that result is to be avoided, and a valuable method of research is to be given its proper place, the medical worker, and his readers, must be at least on speaking terms with the elements of statistical reasoning and methods of analysis, and thus be able themselves to weigh numerical evidence justly in the balance. In short, I should replace my querying title, "Statistics in the Medical Curriculum ?" by "What Statistics in the Medical Curriculum ?" (though I am well aware that some clinical teachers will prefer to read it as "What! Statistics in the Medical Curriculum?").

\section{The Need for Accuracy}

To begin with, on the preventive side of medicine I believe that it is very important that the embryo doctor should be made fully aware of the uses to which statistics of mortality and morbidity are continuously put in public health work, epidemiology, and social medicine. He (or she) is not only sometimes, if he chooses, the consumer of those figures but, whether he chooses or not, is invariably their manufacturer. It is upon the original clinical judgment and diagnosis that the whole subsequent edifice must be built, and our attempts to illustrate the national trends of disease and death, and to solve the problems of epidemics and sickness as a community phenomenon, must be materially aided or hindered by the standard of accuracy that is possible at any given time and place. The student should therefore be taught that it is highly important that he give, so far as he can-as Farr wrote quite a long time ago (1839) - " an authentic name of the fatal disease." Such records are not merely ephemeral bits of paper to satisfy legal requirements but are fundamentail to the national vital-statistical system and serious contributions to the problems of the preventive field.

Of course there will be difficulties; diagnosis and certification are not easy tasks, and the aids to them and their resulting accuracy must change from time to time. The medical statistician is perfectly aware of that. But if we await perfection we shall wait for ever, and so long as we are not ignorant of the imperfections much can be learnt from these imperfect records of mortality and sickness. The medical student, in my view, should, to encourage his interest in this field, be shown at some point in his clinical studies the main uses to which are put the raw material of which he is the producer and briefly how they are statistically treated-for example, by reference to publications of the Registrar-General. In short, as inevitable producer he should be encouraged to give of his best in this respect in his medical career, and as possible consumer he should be made aware of the limitations of the resulting data and thus be able to take a balanced view of them. It 